\title{
Caracterização química de substância isolada das folhas de Argemone mexicana L. e ensaios de viabilidade celular e atividade antibacteriana: abordagem in vitro
}

\author{
Chemical characterization of isolated substance of Argemone mexicana L. leaves and cell viability \\ assays and antibacterial activity: in vitro approach \\ Caracterización química de sustancia aislada de hojas de Argemone mexicana L. y ensayos de \\ viabilidad celular y actividad antibacteriana: enfoque in vitro
}

\author{
Maria Gabriella Silva Araujo \\ ORCID: https://orcid.org/0000-0003-0495-3362 \\ Universidade Federal de Alagoas, Brasil \\ E-mail: gabriellaaraujo2@hotmail.com \\ Regina Célia Sales Santos \\ ORCID: https://orcid.org/0000-0002-2447-0707 \\ Universidade Federal de Alagoas, Brasil \\ E-mail: reginasales@eenf.ufal.br \\ Lucianna Costa de Almeida Barbosa \\ ORCID:https://orcid.org/0000-0001-7797-723X \\ Universidade Federal de Alagoas, Brasil \\ E-mail: lucianna28@gmail.com \\ Wanderlei Barbosa Dos Santos \\ ORCID:https://orcid.org/0000-0001-9813-8857 \\ Universidade Federal de Alagoas, Brasil \\ E-mail: wanderley89@ live.com \\ Edeildo Ferreira Silva-Junior \\ ORCID:https://orcid.org/0000-0002-1527-4501 \\ Universidade Federal de Alagoas, Brasil \\ E-mail: edeildojr@hotmail.com \\ João Xavier de Araújo Júnior \\ ORCID:https://orcid.org/0000-0003-3187-183X \\ Universidade Federal de Alagoas, Brasil \\ E-mail:jotaaraujo2004@gmail.com
}

\begin{abstract}
Resumo
Objetivo: O isolamento e caracterização química de uma substância extraída das folhas da espécie Argemone mexicana L. foi realizado. Além disso, a atividade antibacteriana e de viabilidade celular desta substância foi determinada. Métodos: O isolamento da substância foi realizado por meio da cromatografia em camada líquida clássica, para a caracterização química foram feitas espectroscopia no Infravermelho e de Ressonância Magnética Nuclear. A atividade antibacteriana foi determinada por meio do metódo de microdiluição em caldo a fim de determinar a concentração inibitória mínima da substância. $\mathrm{O}$ ensaio de viabilidade celular foi realizado com o método colorimétrico do 3-(4,5-dimethyl-2-thiazolyl)-2,5-diphenyl-2Htetrazoliumbromide utilizando linhagens de macrófagos J774. Resultados: A substância isolada da espécie Argemone mexicana L. foi identificada como sendo o alcaloide berberina. A capacidade de manter células viáveis da substância foi positiva, visto que ela não só manteve as células viáveis como também promoveu a proliferação dos macrófagos tratados. Este alcaloide exibiu promissora atividade antibacteriana frente a cepas Gram positivas e negativas, principalmente frente a espécie Pseudomonas aeruginosa numa concentração de $62,5 \mu \mathrm{g} / \mathrm{ml}$. Conclusão: A capacidade da berberina em manter e proliferar células e inibir o crescimento bacteriano sugere seu potencial para tratamento futuro como antimicrobiano e em patologias que necessitam de estímulo na proliferação celular.
\end{abstract}

Palavras-chave: Argemone mexicana L.; Antibacterianos; Sobrevivência celular; Berberina.

\begin{abstract}
Aim: Isolation and chemical characterization of a substance extracted from leaves of the species Argemone mexicana L. was performed. In addition, the antibacterial activity and cell viability of this substance was determined. Method: The isolation of the substance was performed by classical liquid layer chromatography, for the chemical characterization were made Infrared and Nuclear Magnetic Resonance spectroscopy. Antibacterial activity was determined by the broth microdilution method to determine the minimum inhibitory concentration of the substance.
\end{abstract}


The cell viability assay was performed with the 3- (4,5-dimethyl-2-thiazolyl) -2,5-diphenyl-2Htetrazoliumbromide colorimetric method using J774 macrophage strains. Results: The substance isolated from the species Argemone mexicana L. was identified as berberine alkaloid. The ability to maintain viable cells of the substance was positive, as it not only maintained viable cells but also promoted proliferation of treated macrophages. This alkaloid demonstrated promising antibacterial activity against Gram positive and negative strains, mainly against Pseudomonas aeruginosa at a concentration of $62,5 \mu \mathrm{g} / \mathrm{ml}$. Conclusion: Berberine's ability to maintain and proliferate cells and inhibit bacterial growth suggests its potential for future antimicrobial treatment and in conditions that require stimulation of cell proliferation.

Keywords: Argemone mexicana L.; Anti-bacterial agents; Cell survival; Berberine.

\section{Resumen}

Objetivo: Se realizó el aislamiento y caracterización química de una sustancia extraída de hojas de la especie Argemone mexicana L. Además, se determinó la actividad antibacteriana y la viabilidad celular de esta sustancia. Método: El aislamiento de la sustancia se realizó mediante cromatografía en capa líquida clásica, para la caracterización química se realizó espectroscopía de Infrarrojos y Resonancia Magnética Nuclear. La actividad antibacteriana se determinó mediante el método de microdilución en caldo para determinar la concentración inhibitoria mínima de la sustancia. El ensayo de viabilidad celular se realizó con el método colorimétrico de bromuro de 3- (4,5-dimetil-2-tiazolil) -2,5-difenil-2Htetrazolio utilizando cepas de macrófagos J774. Resultados: La sustancia aislada de la especie Argemone mexicana L. fue identificada como alcaloide berberina. La capacidad de mantener células viables de la sustancia fue positiva, ya que no solo mantuvo células viables sino que también promovió la proliferación de macrófagos tratados. Este alcaloide demostró una actividad antibacteriana prometedora contra cepas Gram positivas y negativas, principalmente contra Pseudomonas aeruginosa a una concentración de $62,5 \mu \mathrm{g} / \mathrm{ml}$. Conclusión: La capacidad de la berberina para mantener y proliferar células e inhibir el crecimiento bacteriano sugiere su potencial para futuros tratamientos antimicrobianos y en condiciones que requieren estimulación de la proliferación celular.

Palabras clave: Argemone mexicana L.; Antibacterianos; Supervivencia celular; Berberine.

\section{Introdução}

As doenças infecciosas são responsáveis por um terço da mortalidade global (WHO, 2017) e o desenvolvimento de antimicrobianos proporcionou uma relevante diminuição na taxa de mortalidade por infecções bacterianas (SOSIC et al., 2015) No entanto, isso continua sendo um grave problema de saúde para a sociedade, já que a presença de infecções compromete a vida das pessoas e a economia global de forma significativa (RAR, 2014). O aparecimento recorrente de epidemias bacterianas e o surgimento de novas cepas patogênicas impulsiona a descoberta de novos antibióticos, sejam eles de origem sintética ou natural (Cos et al., 2006; Harvey, Edrada-Ebel, Quinn, 2015).

Desde os primórdios, as plantas medicinais são utilizadas como uma alternativa para o tratamento de doenças. Uma grande variedade de antimicrobianos foram originados por meio de muitas investigações fitoquímicas e farmacológicas de plantas medicinais (Heinrich et al., 2017). Neste contexto, encontra-se a espécie vegetal Argemone mexicana L. que é uma erva daninha encontrada na América central, mas com grande distribuição em diversos países tropicais e sub-tropicais, incluindo África Ocidental (Ibrahim et al., 2009).

A espécie vegetal Argemone mexicana Linn apresenta diversos compostos secundários de grande importância biológica em toda sua estrutura, como alcaloides, esteroides livres, cumarinas, antronas (Araujo et al., 2015) flavonoides, fenois, saponinas, taninos, glicosídeos (Joshi et al. 2013).

Foi observado que a fração metanólica do extrato de folhas de Argemone mexicana L. exibiu atividade antibacteriana frente a cepas de Staphylococcus aureus e Staphylococcus (Araujo et al. 2015). Diante disso o presente estudo teve como objetivo isolar e identificar o metabólito secundário majoritário presente na fração metanólica do extrato bruto das folhas de Argemone mexicana L., além de determinar se este composto possui atividade antibacteriana frente a estirpes Gram positivas (S. aureus e S. epidermidis) e Gram negativas (Escherichia coli e Pseudomonas aeruginosa), bem como verificar a sua capacidade de manter linhagens de macrófagos viáveis. 


\section{Metodologia}

\section{Material da planta e isolamento do metabólito}

A espécie Argemone mexicana Linn foi coletada na cidade de Arapiraca, interior do estado de Alagoas, no nordeste do Brasil e identificada por técnicos do herbário MAC do Instituto de Meio Ambiente do estado de Alagoas sob registro 57421. O extrato bruto foi preparado conforme já realizado na literatura [8]. Para o preparo da fração metanólica foram utilizadas $115 \mathrm{~g}$ do extrato bruto, o qual foi fracionado em coluna filtrante sob vácuo, utilizando como fase estacionária a sílica gel e como fase móvel os solventes: hexano $\left(\mathrm{CH}_{3}\left(\mathrm{CH}_{2}\right)_{4} \mathrm{CH}_{3}\right)$, clorofórmio $\left(\mathrm{CHCl}_{3}\right)$, acetato de etila $(\mathrm{AcOEt})$ e metanol $(\mathrm{MeOH})$, com $600 \mathrm{ml}$ de cada. A fração metanólica, amostra de interesse, foi colocada para secar em temperatura ambiente.

Para isolamento do metabólito secundário, a fração metanólica foi submetida a uma cromatografia em coluna líquida clássica, onde foram utilizados $7 \mathrm{~g}$ da fração metanólica associado a $21 \mathrm{~g}$ de sílica. A amostra foi colocada em evaporador rotativo até adquirir forma de pó, em seguida esta amostra foi colocada acima da fase estacionária e recoberta pelo sistema de solventes escolhidos em uma proporção de 9:1 de Clorofórmio e Metanol.

Ao fim do processo de cromatografia, foi coletado um capilar de cada tubo de ensaio contendo soluções da amostra e submetidos a uma cromatografia em camada delgada com o objetivo de identificar o grau de pureza e similaridade entre os tubos, os quais foram agrupados e submetidos a rotoevaporação para concentração da amostra e posterior secagem à temperatura ambiente.

\section{Caracterização Química do composto isolado}

A amostra isolada da fração metanólica da espécie vegetal Argemone mexicana Linn foi submetida a uma espectroscopia no Infravermelho em um espectrômetro Perkin-Elmer modelo 720, com acessório de Refletância Total Atenuada (RTA), um cristal de germânio.

Posteriormente, foi realizada uma espectroscopia de ressonância magnética nuclear na substância isolada, a qual foi exposta a um campo magnético de vários teslas (T), o que leva os núcleos de interesse aos estados de energia necessários para que ocorra a absorção de radiação, determinando assim a estrutura e dinâmica molecular. Espectros de $\mathrm{RMN}$ de ${ }^{1} \mathrm{H}$ e ${ }^{13} \mathrm{C}$ foram registrados a $25{ }^{\circ} \mathrm{C}$ a $400 \mathrm{MHz}$ e $100 \mathrm{MHz}$, respectivamente, em um instrumento Bruker® Avance utilizando TMS como padrão interno, e DMSO-d6 como solvente. Os desvios químicos ( $\delta$ ) foram dados em partes por milhão (ppm), e constante de acoplamento (J) em Hertz.

\section{Ensaio de viabilidade celular}

O componente isolado foi submetido ao método colorimétrico do 3-(4,5-dimethyl-2-thiazolyl) -2,5-diphenyl2Htetrazoliumbromide (MTT), baseado na atividade mitocondrial das células pela redução do MTT [(MOSMANN, 1983).

Foram utilizados macrófagos da linhagem J774, os quais foram tratados pela substância isolada nas concentrações de 500, 100, $10 \mu \mathrm{g} / \mathrm{mL}$ por 48 horas e mantidas em estufa a $5 \%$ de $\mathrm{CO}_{2}$. Para a quantificação do sal de formazan reduzido, as placas foram lidas com o auxílio de um leitor de microplacas no comprimento de onda $550 \mathrm{~nm}$.

\section{Atividade antibacteriana}

A atividade antibacteriana foi determinada utilizando o método de Concentração Inibitória Mínima (CIM) (CLSI, 2012). As seguintes linhagens da American Type Culture Collection (ATCC) foram utilizadas para avaliação da atividade antibacteriana da substância isolada, Gram positiva: Staphylococcus aureus (ATCC 25923) e Staphylococcus epidermidis (ATCC 14990) e Gram negativas: Escherichia coli (ATCC 25922) e Pseudomonas aeruginosa (ATCC 27853). 
Foi utilizado o método de microdiluição em caldo com a substância isolada numa concentração de $1 \mathrm{mg} / \mathrm{mL}$, o teste foi realizado em triplicata em microplacas de 96 poços, onde cada coluna possuiu uma concentração decrescente de $500 \mu \mathrm{g} / \mathrm{mL}$ a 3,9062 $\mu \mathrm{g} / \mathrm{mL}$. Cada poço recebeu $10 \mu \mathrm{L}$ de inóculo bacteriano $\left(5 \times 10^{4} \mathrm{UFC} / \mathrm{mL}\right)$ e em seguida as placas foram incubadas a $35^{\circ} \mathrm{C}$ durante 18 horas. Após este período, cada poço recebeu $20 \mu \mathrm{L}$ de 2,3,5-trifenil tetrazólio e uma nova incubação por 3 horas a $35^{\circ} \mathrm{C}$. O poço com menor concentração sem a presença da coloração vermelha do 2,3,5-trifenil tetrazólio representou a CIM da substância para cada estirpe bacteriana.

\section{Análise estatística}

Para o ensaio de MTT, os dados foram expressos como média das absorbâncias \pm SEM e diferenças estatísticas entre os grupos tratados e os de controle foram avaliadas por ANOVA e teste de Dunnett, considerando significância estatística com $\mathrm{p}<0,05$, utilizando o software GraphPad Prism ${ }^{\circledR}$ versão 5.0. O percentual de viabilidade celular foi calculado de acordo com a absorbância do controle positivo e do isolado, utilizando a seguinte fórmula:

$\%$ Viabilidade $=100 \times \frac{\text { Absorbância de células tratadas }}{\text { Absorbância células não tratadas }}$

\section{Resultados e Discussão}

\section{Isolamento e caracterização química do metabólito secundário}

A fração metanólica foi submetida a uma coluna líquida clássica a fim de isolar o componente majoritário presente na amostra, foi utilizado $7 \mathrm{~g}$ de fração metanólica em um sistema de solventes Clorofórmio - Metanol numa proporção de 9:1.

Ao final do processo foram coletados 25 frascos com soluções da amostra, onde uma alíquota de cada frasco foi submetida a uma cromatografia em camada delgada analítica (CCDA) a fim de identificar quais frascos continham o isolado do componente majoritário.

Os frascos que apresentaram similaridade de mancha na CCDA foram agrupados e concentrados em evaporador rotativo. Após secagem à temperatura ambiente, a amostra apresentou um rendimento final de substância isolada de $196 \mathrm{mg}$.

A substância isolada foi submetida a espectroscopia de absorção no infravermelho onde foi observada a presença dos seguintes grupos funcionais presentes na molécula: estiramento $\mathrm{C}-\mathrm{H}$ em $2852 \mathrm{~cm}^{-2}$, estiramento $\mathrm{C}=\mathrm{C}, \mathrm{C}=\mathrm{N}$ em $1601 \mathrm{~cm}^{-2}$, deformação C-H entre 1360-1388 cm-2 e, ainda, um estiramento em $1063 \mathrm{~cm}^{-2}$ referente à ligação C-O (Figura 1).

Figura 1. Espectroscopia de infravermelho de substância isolada de Argemone mexicana L.

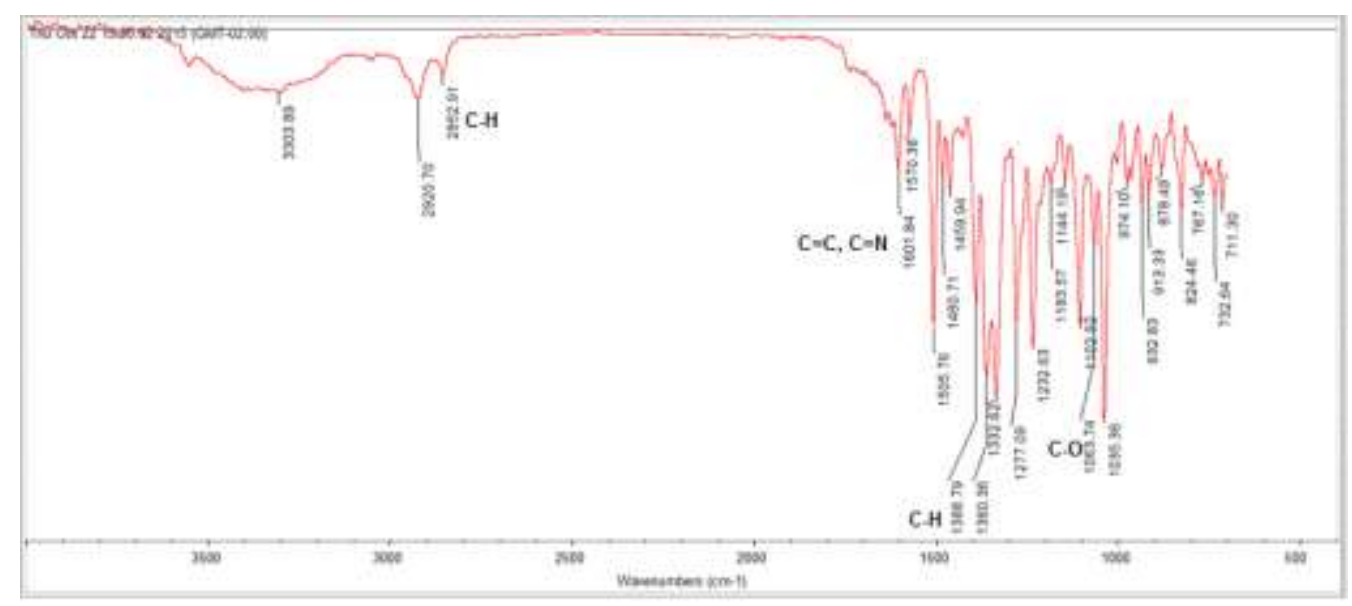

Fonte: Dados da pesquisa, Maceió, Alagoas (2021). 
Quanto a espectroscopia de ressonância magnética nuclear, os deslocamentos químicos do espectro de $\mathrm{RMN}$ de ${ }^{1} \mathrm{H}$ (Figura 2) e RMN ${ }^{13} \mathrm{C}$ (Figura 3) obtidos do composto isolado foram comparados aos encontrados na literatura (Blasko, 1988), o que foi possível confirmar que se trata do alcaloide berberina.

Figura 2. Espectroscopia de $\mathrm{RMN}{ }^{1} \mathrm{H}$ em DMSO-d6 da substância isolada extraída das folhas de Argemone mexicana L.

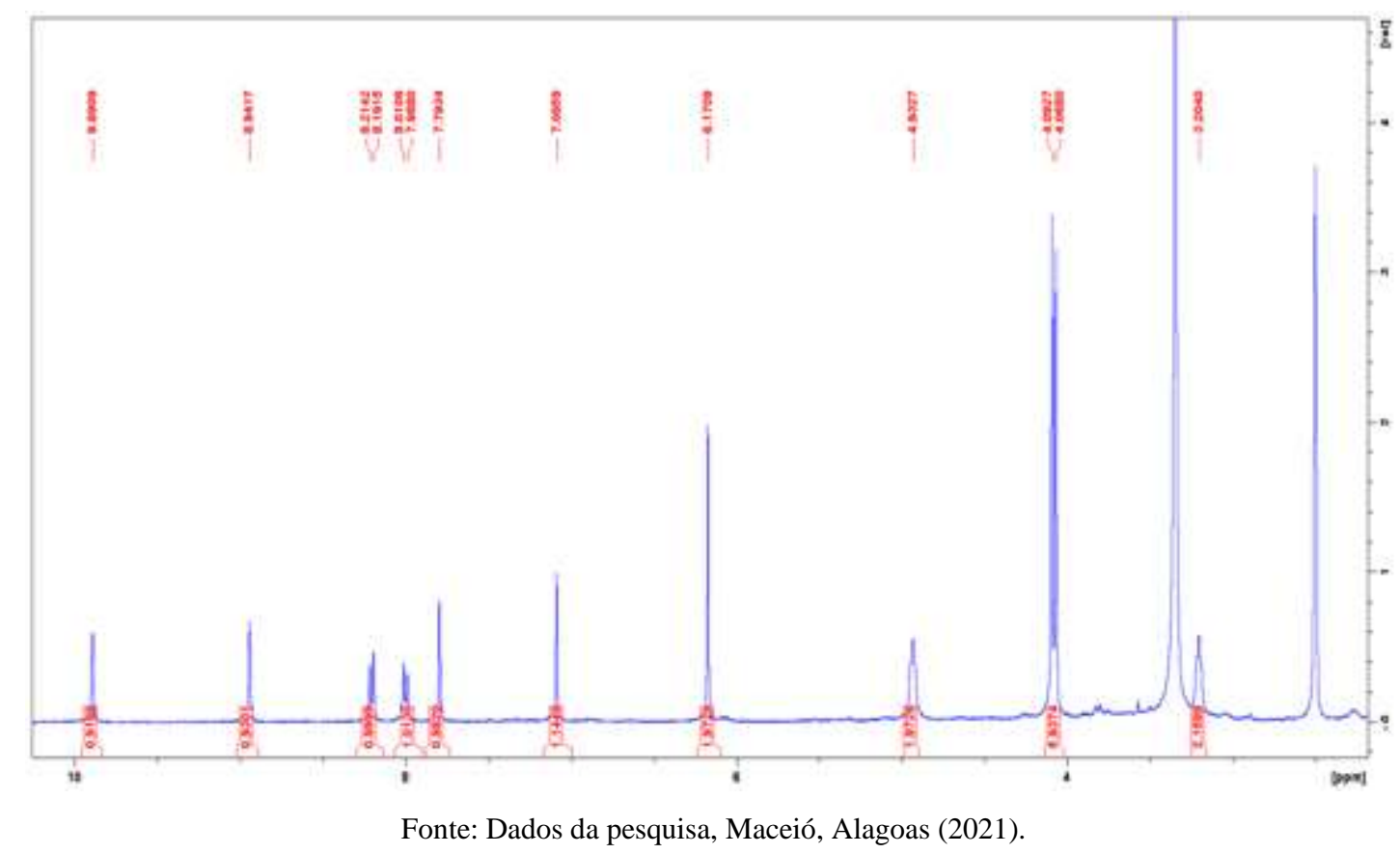

Figura 3. Espectros de RMN ${ }^{13} \mathrm{C}$ em DMSO-d6 da substância isolada extraída das folhas de Argemone mexicana L.

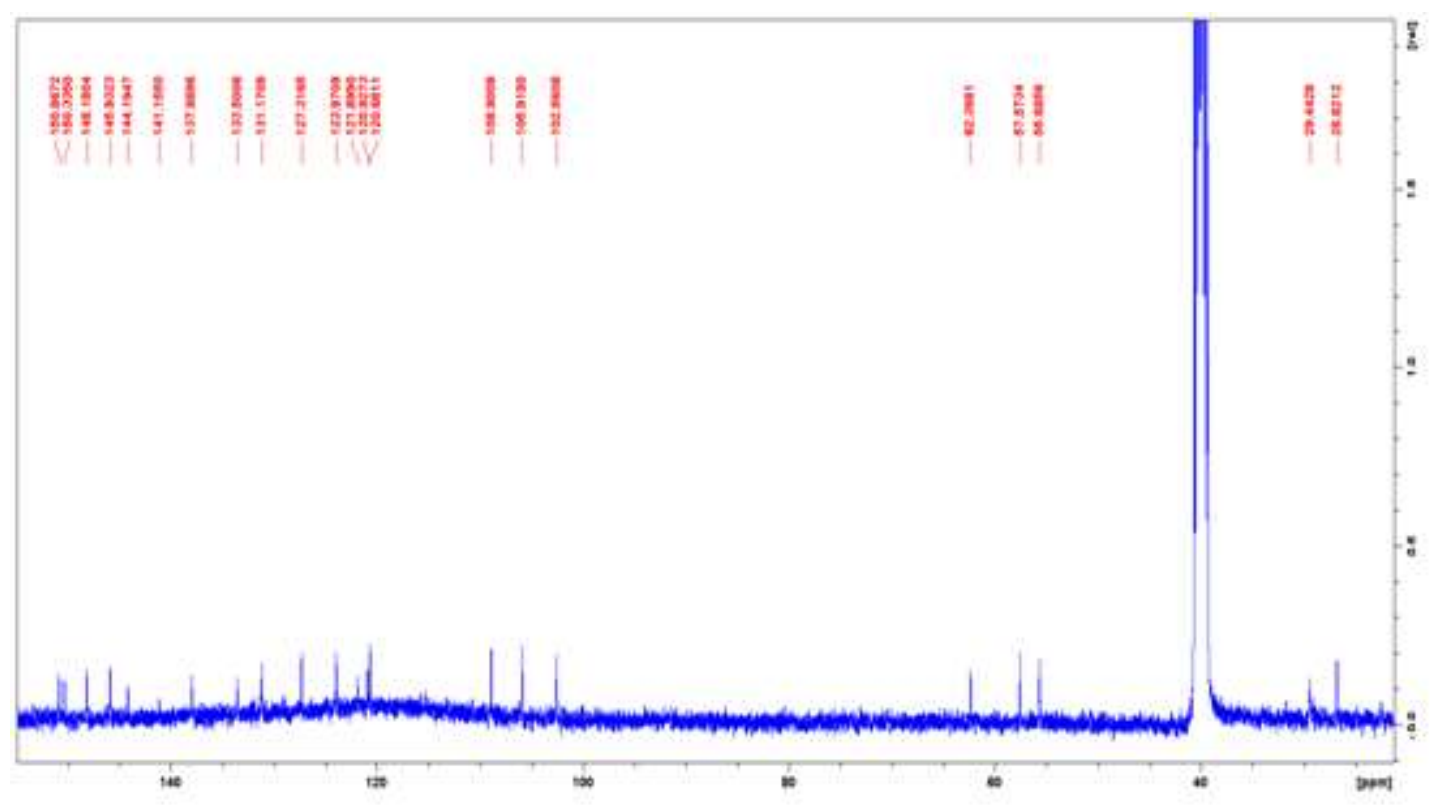

Fonte: Dados da pesquisa, Maceió, Alagoas (2021).

\subsection{Ensaio de viabilidade celular}

A toxicidade é um dos fatores que limita a liberação e consumo de fármacos, sua avaliação é realizada com o objetivo de determinar o potencial de novas substâncias em causar danos à saúde, bem como estabelecer sua aplicabilidade e índice 
terapêutico (Valadares, 2006). A berberina foi submetida ao teste de citotoxicidade pelo método colorimétrico de Metiltetrazolium. Linhagens de macrófagos $\mathrm{J} 774$ foram tratadas com o isolado nas concentrações de 500, 100 e $10 \mu \mathrm{g} / \mathrm{mL}$ (Figura 4).

O isolado, na concentração de $500 \mu \mathrm{g} / \mathrm{mL}$, não apresentou citotoxicidade relevante para os macrófagos $\mathbf{J} 774$, pois conseguiu manter cerca de $69,38 \%$ das células viáveis. Já na concentração de $100 \mu \mathrm{g} / \mathrm{mL}$, a berberina não apresentou citotoxicidade, visto que exibiu proliferação celular com um percentual de 107,48\%. O mesmo aconteceu com as células que foram tratadas com o isolado na concentração de $10 \mu \mathrm{g} / \mathrm{mL}$, com um percentual de viabilidade celular de 119,13\%. Resultados similares foram encontrados em ensaios de MTT que avaliaram a viabilidade celular da berberina sintética (Gu et al., 2015; da Silva et al., 2016).

Figura 4. Ensaio de viabilidade celular da berberina, pelo método colorimétrico do Metiltetrazolium, nas concentrações de 500 $\mu \mathrm{g} / \mathrm{mL}, 100 \mu \mathrm{g} / \mathrm{mL}$ e $10 \mu \mathrm{g} / \mathrm{mL}$ para as linhagem de macrófagos $\mathrm{J} 774$.

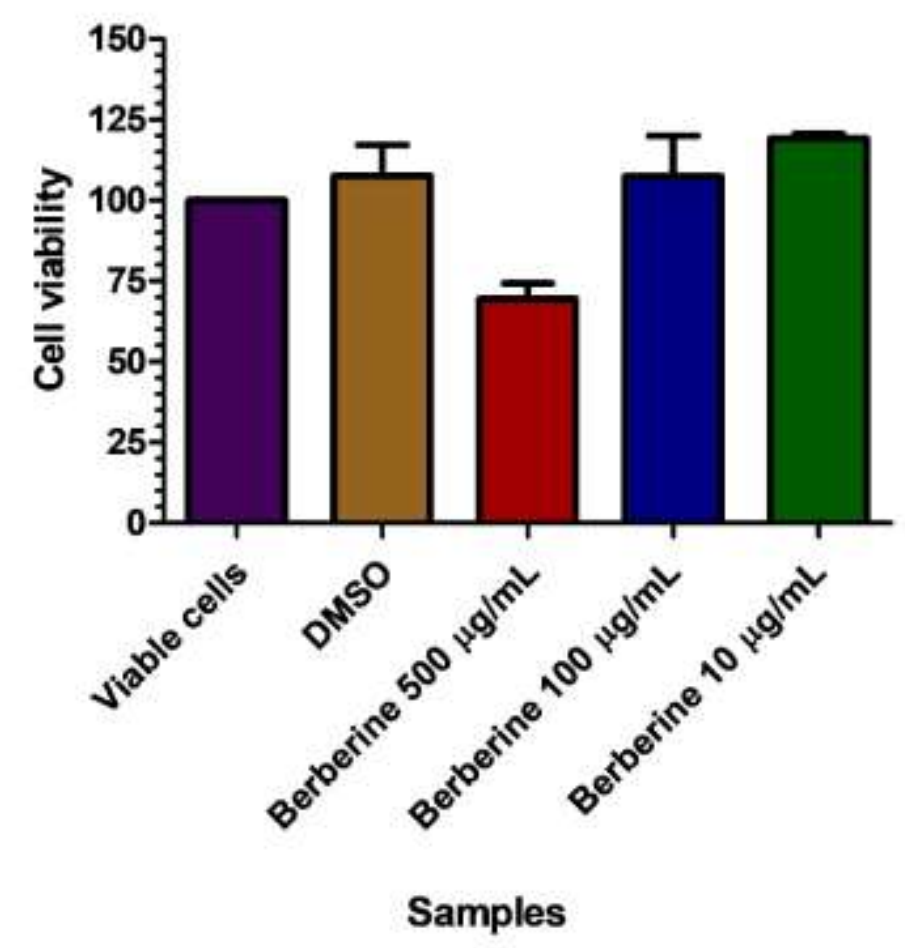

Fonte: Dados da pesquisa, Maceió, Alagoas (2021).

\subsection{Atividade antibacteriana}

A berberina foi submetida ao teste de microdiluição em caldo a fim de determinar sua concentração inibitória mínima (CIM) frente às quatro principais estirpes de bactérias Gram positivas e Gram negativas causadoras de infecção em feridas.

A amostra foi testada numa concentração de $500 \mu \mathrm{g} / \mathrm{ml}$ e nos resultados obtidos exibiu atividade antibacteriana frente aos quatro tipos de microrganismos testados, apresentando uma CIM que variou de 250 - 62,5 $\mu \mathrm{g} / \mathrm{ml}$ (Tabela 1). 
Tabela 1 Concentração Inibitória Mínima (CIM) do isolado berberina, pelo teste da microdiluição em caldo, frente às cepas bacterianas Gram positivas e Gram negativas em microgramas por mililitro $(\mu \mathrm{g} / \mathrm{ml})$

\begin{tabular}{cc}
\hline \multicolumn{2}{c}{ Concentração Inibitória Mínima - CIM } \\
\hline Cepas bacterianas & Concentração $(\mu \mathrm{g} / \mathrm{ml})$ \\
\hline Staphylococcus aureus & 125 \\
Staphylococcus epidermidis & 125 \\
Escherichia coli & 250 \\
Pseudomonas aeruginosa & 62,5 \\
\hline
\end{tabular}

Nota: condições de cultivo bacteriano: caldo Mueller-Hinton, $35^{\circ} \mathrm{C}$. Fonte: Dados da pesquisa, Maceió, Alagoas (2021).

A berberina apresentou melhor ação antibacteriana frente à estirpe $P$. aeruginosa, pertencente ao grupo das Gram negativas, com uma CIM de 62,5 $\mathrm{gg} / \mathrm{ml}$. A literatura afirma que derivados de berberina exibiram uma CIM abaixo de 64 $\mu \mathrm{g} / \mathrm{mL}$ frente a essa cepa (Wen et al., 2016), o que corrobora com o potencial antibacteriano do presente estudo.

Pesquisas referem que a berberina foi utilizada com a finalidade de diminuir a resistência de antibióticos como eritromicina, ciprofloxacino, tetraciclina, amicacina e getamicina frente a diversas cepas de $P$. aeruginosa resistentes, onde a associação deste isolado com os antibióticos conseguiu reduzir em até 8 vezes a concentração inibitória mínima destes antibióticos (Morita et al., 2016).

Para E. coli, a berberina exibiu atividade antibacteriana de $250 \mu \mathrm{g} / \mathrm{mL}$, sendo este resultado compatível com outro encontrado na literatura. A atividade da beberina frente a estirpes de E. coli isoladas de diarreia hemorrágica, que eram resistentes a mais de seis antibióticos, demonstrou que essa substância pode atuar como um eficiente antibacteriano para essa cepa (Bandyopadhyay et al., 2013).

Quando testado frente à microrganismos pertencentes ao grupo das Gram positivas, o isolado foi capaz de inibir o crescimento de $S$. aureus e $S$. epidermidis com CIM de $125 \mu \mathrm{g} / \mathrm{ml}$, o que demonstra sua atividade promissora, uma vez que a $S$. aureus é considerada como um dos mais importantes patógenos causadores de processos infecciosos, pois é capaz de abranger lesões superficiais até severas infecções sistêmicas. Sua virulência é resultado da existência de inúmeras toxinas; enzimas e proteínas associadas à sua parede celular que combinados causam a invasão tecidual e a sobrevivência no sítio infeccioso; além de ter forte resistência adquirida aos mais diversos antimicrobianos (Catão et. al. 2010).

A berberina apresenta atividade antibacteriana devido a sua capacidade de inibir a síntese de proteínas que estão associadas no crescimento das bactérias, bem como, é capaz de bloquear a divisão e desenvolvimento desses microrganismos (Kang et al., 2015).

\section{Conclusão}

Com base nos resultados do presente estudo, foi possível observar que o metabólito secundário presente na fração metanólica das folhas de Argemone mexicana L. foi identificado como o alcaloide berberina e que a ele é atribuído a responsabilidade pela atividade antibacteriana frente às cepas bacterianas Gram positivas $S$. aureus (125 $\mu \mathrm{g} / \mathrm{ml})$ e $S$. epidermidis $(125 \mu \mathrm{g} / \mathrm{ml})$ e Gram negativas E. coli $(250 \mu \mathrm{g} / \mathrm{ml})$ e P. aeruginosa $(62,5 \mu \mathrm{g} / \mathrm{ml})$. Além disso, a berberina não apresenta citotoxicidade frente a linhagens de macrófagos J774. Este alcaloide não só manteve as células viáveis como também foi capaz de promover a proliferação dessas células. 


\section{Referências}

Araujo, M. G. S., Silva, A. L. L., Silva-Junior, E. F., Santos Junior, P. F. S., Santos, M., \& Veríssimo, R. C. S. S. (2015). Evaluation of antimicrobial and cytotoxic potential of Argemone mexicana L. Journal of Chemical and Pharmaceutical Research, 7(12), 482-489

Bandyopadhyay, S., Patra, P. H., Mahanti, A., Mondal, D. K., Dandapat, P., Bandyopadhyay, S., \& Baruah, K. K. (2013). Potential antibacterial activity of berberine against multi drug resistant enterovirulent Escherichia coli isolated from yaks (Poephagus grunniens) with haemorrhagic diarrhoea. Asian Pacific journal of tropical medicine, 6(4), 315-319.

Blasko, G., Cordell, G. A., Bhamarapravati, S., \& Beecher, C. W. (1988). Carbon-13 NMR assignments of berberine and sanguinarine. Heterocycles (Sendai), 27(4), 911-916

Catão, R. M., Barbosa-Filho, J. M., Lima, E. D. O., Pereira, M. D. S. V., Silva, M. A. R. D., Arruda, T. A. D., \& Antunes, R. M. P. (2010). Avaliação da atividade antimicrobiana e efeitos biológicos de riparinas sobre eliminação de resistência a drogas em amostras de Staphylococcus aureus. Rev. bras. anal. clin, 9-14.

Clinical and Laboratory Standards Institute CLSI, Performance Standards for Antimicrobial Susceptibility Testing; Twenty-Second. Documents. M100-S22. (2012).

Cos, P., Vlietinck, A. J., Berghe, D. V., \& Maes, L. (2006). Anti-infective potential of natural products: How to develop a stronger in vitro 'proof-of-concept'. Journal of ethnopharmacology, 106(3), 290-302.

da Silva, A. R., de Andrade Neto, J. B., da Silva, C. R., Campos, R. D. S., Costa Silva, R. A., Freitas, D. D., \& Nobre Júnior, H. V. (2016). Atividade antifúngica da berberina em leveduras patogênicas resistentes ao fluconazol: mecanismo de ação avaliado por citometria de fluxo e inibição do crescimento de biofilme em Candida spp. Agentes antimicrobianos e quimioterapia, 60 (6), 3551-3557.

Gu, M., Xu, J., Han, C., Kang, Y., Liu, T., He, Y., \& Liu, C. (2015). Effects of berberine on cell cycle, DNA, reactive oxygen species, and apoptosis in L929 murine fibroblast cells. Evidence-Based Complementary and Alternative Medicine, 2015.

Harvey, A. L., Edrada-Ebel, R., \& Quinn, R. J (2015). O ressurgimento de produtos naturais para a descoberta de medicamentos na era da genômica. Nature reviews drug discovery, 14 (2), 111-129.

Heinrich, M., Williamson, E. M., Gibbons, S., Barnes, J., \& Prieto-Garcia, J. (2017). Fundamentals of pharmacognosy and phytotherapy E-BOOK. Elsevier Health Sciences.

Ibrahim, H. A., \& Ibrahim, H. (2009). Phytochemical screening and toxicity evaluation on the leaves of Argemone mexicana Linn.(Papaveraceae). International Journal of Applied Sciences, 3, 39-43.

Joshi, N., Bhatt, S., Dhyani, S., \& Nain, J. (2013). Phytochemical screening of secondary metabolites of Argemone mexicana linn. flowers. Int J Curr Pharm Res, 5(2), 144-147.

Kang, S., Li, Z., Yin, Z., Jia, R., Song, X., Li, L., \& Yin, L. (2015). The antibacterial mechanism of berberine against Actinobacillus pleuropneumoniae. Natural product research, 29(23), 2203-2206.

Morita, Y., Nakashima, K. I., Nishino, K., Kotani, K., Tomida, J., Inoue, M., \& Kawamura, Y. (2016). Berberine is a novel type efflux inhibitor which attenuates the MexXY-mediated aminoglycoside resistance in Pseudomonas aeruginosa. Frontiers in microbiology, 7, 1223.

Mosmann, T. (1983). Ensaio colorimétrico rápido para crescimento e sobrevivência celular: aplicação a ensaios de proliferação e citotoxicidade. Journal of immunological methods, 65 (1-2), 55-63.

Review on Antimicrobial Resistance. (2014). Antimicrobial resistance: tackling a crisis for the health and wealth of nations. Review on Antimicrobial Resistance.

Sosic, I., Anderluh, M., Sova, M., Gobec, M., Mlinarič Raščan, I., Derouaux, A., \& Gobec, S. (2015). Structure-activity relationships of novel tryptaminebased inhibitors of bacterial transglycosylase. Journal of medicinal chemistry, 58(24), 9712-9721.

Valadares, M. C. (2006). Avaliação de toxicidade aguda: estratégias após a "era do teste dl50 “. Revista Eletrônica de Farmácia, 3(2).

Wen, S. Q., Jeyakkumar, P., Avula, S. R., Zhang, L., \& Zhou, C. H. (2016). Discovery of novel berberine imidazoles as safe antimicrobial agents by down regulating ROS generation. Bioorganic \& medicinal chemistry letters, 26(12), 2768-2773.

World Health Organization. (2017). Fact sheet: the top 10 causes of death. World Health Organization. 